\title{
Salt appetite in the elderly
}

\author{
Khadeja Hendi and Micah Leshem* \\ Department of Psychology, University of Haifa, Haifa 3498838, Israel
}

(Submitted 25 April 2014 - Final revision received 28 July 2014 - Accepted 6 August 2014 - First published online 7 October 2014)

\begin{abstract}
The present study investigated whether salt appetite in the elderly is impaired similar to thirst because of the commonality of their physiological substrates and whether alterations in salt appetite are related to mood. Elderly (65-85 years, $n$ 30) and middle-aged (45-58 years, $n$ 30) men and women were compared in two test sessions. Thirst, psychophysical ratings of taste solutions, dietary Na and energy intakes, seasoning with salt and sugar, number of salty and sweet snacks consumed, preferred amounts of salt in soup and sugar in tea, and an overall measure of salt appetite and its relationship with mood, nocturia and sleep were measured. Elderly participants were found to be less thirsty and respond less to thirst. In contrast, no impairment of salt appetite was found in them, and although they had a reduced dietary $\mathrm{Na}$ intake, it dissipated when corrected for their reduced dietary energy intake. Diet composition and Na intake were found to be similar in middle-aged and elderly participants, despite the lesser intake in elderly participants. There were no age-related differences in the intensity of taste or hedonic profile of $\mathrm{Na}$, in salting habits, in tests of salting soup, or number of salty snacks consumed. No relationship of any measure of salt appetite with mood measured by the Positive and Negative Affect Schedule, frequency of nocturia, or sleep duration was observed. The age-related impairment of the physiology of mineralofluid regulation, while compromising thirst and fluid intake, spares salt appetite, suggesting that salt appetite in humans is not regulated physiologically. Intact salt appetite in the elderly might be utilised judiciously to prevent hyponatraemia, increase thirst and improve appetite.
\end{abstract}

Key words: Elderly: Diets: Salt appetite: Thirst

Euhydration depends on adequate $\mathrm{Na}$ and water intakes, mediated by shared physiological and neural substrates ${ }^{(1,2)}$. Thirst is an emotion essential for survival, and its physiological instigators are volumetric or osmotic changes in the intracellular, interstitial and intravascular body fluid compartments. Thirst can also be aroused by oral dryness, high concentrations of oral $\mathrm{Na}$, and cognitive, associative and appetitive circumstances ${ }^{(3)}$.

However, in the elderly, impaired thirst may compromise euhydration and in extreme heat may significantly contribute to mortality ${ }^{(4-9)}$. The dangers of hyponatraemia in general are increasingly recognised, and they increase with age. Electrolyte disorders are common among the elderly, often due to the syndrome of inappropriate antidiuretic hormone secretion, or associated with diabetes mellitus and diuretic use in hypertension. Elderly who use both thiazides and benzodiazepines have a more severe degree of hyponatraemia. Even mild electrolyte disorder is associated with mortality and chronic hyponatraemia is associated with bone density loss and fractures ${ }^{(4,5,7,10,11)}$.

Salt appetite and thirst are intimately related in animals and, as in humans, their neuroendocrine and physiological regulation processes are intimately related too ${ }^{(1,12)}$. Aged rats consume less water and less $\mathrm{Na}$ when deprived of either, or stimulated with desoxycorticosterone acetate, and have reduced angiotensin 1 and atrial natriuretic peptide receptor mRNA expression in hypothalamus, which are important central mediators of thirst and salt appetite ${ }^{(13-15)}$.

There are substantive differences between animals and humans with regard to salt avidity. In fact, it has been proposed that humans do not have a salt appetite as animals $\mathrm{do}^{(12)}$. Indeed, it is not known whether, similar to thirst, salt appetite is compromised in elderly people. If it is, in addition to making a possible contribution to hyponatraemia, it could aggravate nocturia and increase sleep and mood disturbances, which afflict the elderly more and which have been reported to be variously associated with $\mathrm{Na}$ intake $\mathrm{e}^{(5,16-18)}$.

One of the differences between humans and animals is that animals seek $\mathrm{Na}$ as any salt, whereas humans only seek $\mathrm{NaCl}$, and therefore herein we shall term the human avidity for salt in its various forms as 'salt appetite ${ }^{,(12,19)}$.

In the present study, we compared salt appetite in elderly and middle-aged people to determine possible age-related changes. In addition, we compared their 20-year recalled dietary salt intake to determine whether any changes occurred with time or age.

Abbreviations: NA, negative affect; PANAS, Positive and Negative Affect Schedule.

*Corresponding author: Dr M. Leshem, email micah.leshem@psy.haifa.ac.il 


\section{Methods}

\section{Participants}

Ethics approval for the study was provided by the University of Haifa. A total of sixty individuals from the Arab town of Fureidis volunteered and signed informed consent forms. They were recruited by word of mouth and from day centres for the elderly. Among these volunteers, thirty were middleaged (49.8 (sE 0.7) (45-58) years; sixteen males and fourteen females) and thirty were elderly (73.2 (SE 1.1) (65-85) years; fourteen males and sixteen females). Thus, the average difference between the generations was 23.5 (SE 1.3) years. Data were collected in 2012-13.

\section{Procedure}

The participants were asked to avoid eating and drinking beverages other than water $2 \mathrm{~h}$ before the test sessions. There were two sessions, both conducted at the participants' homes. The first session commenced with signing of the informed consent form including a brief explanation in general terms that the participants would be required to evaluate the taste of various common food items and complete questionnaires about their diet. With the help of the investigators, they completed a brief questionnaire about demographics, smoking status, dieting, health, exercise, nocturia and sleep (Table 1) and completed a dietary questionnaire, the Positive and Negative Affect Schedule (PANAS) mood scale ${ }^{(20)}$ and salt preference tests.

To estimate salt appetite, the participants were tested for preferred amounts of salt in soup and sugar in tea, followed by a test with oral sprays of $\mathrm{NaCl}$ and sucrose solutions. Between the taste tests, the participants were interviewed to

Table 1. Demographics of the study participants

(Mean values with their standard errors, or percentages)

\begin{tabular}{|c|c|c|c|c|c|}
\hline & \multirow{2}{*}{$\begin{array}{c}\text { Age } \\
\text { (years) }\end{array}$} & \multicolumn{2}{|c|}{ Men } & \multicolumn{2}{|c|}{ Women } \\
\hline & & Mean & SEM & Mean & SEM \\
\hline \multirow[t]{2}{*}{ Age groups (years) } & $45-58$ & $50 \cdot 9$ & 0.9 & $49 \cdot 1$ & 1.0 \\
\hline & $65-85$ & $71 \cdot 4^{\star \star *}$ & 1.6 & $75 \cdot 3^{\star * *}$ & 1.4 \\
\hline \multirow[t]{2}{*}{ BMI $\left(\mathrm{kg} / \mathrm{m}^{2}\right)$} & $45-58$ & $27 \cdot 5$ & $2 \cdot 0$ & 36.3††† & $2 \cdot 1$ \\
\hline & $65-85$ & $31 \cdot 2$ & $2 \cdot 1$ & 35.4 & $2 \cdot 0$ \\
\hline \multirow[t]{2}{*}{ Dieting (\%) } & $45-58$ & \multicolumn{2}{|c|}{$31 \cdot 3$} & \multicolumn{2}{|c|}{$57 \cdot 1$} \\
\hline & $65-85$ & \multicolumn{2}{|c|}{$28 \cdot 6$} & \multicolumn{2}{|c|}{$37 \cdot 5$} \\
\hline \multirow[t]{2}{*}{ Limiting salt intake (\%) } & $45-58$ & \multicolumn{2}{|c|}{$18 \cdot 8$} & \multicolumn{2}{|c|}{$14 \cdot 3$} \\
\hline & $65-85$ & \multicolumn{2}{|c|}{$14 \cdot 3$} & \multicolumn{2}{|c|}{$50 \cdot 0^{\star} \dagger$} \\
\hline \multirow{2}{*}{$\begin{array}{l}\text { Working (including } \\
\text { housework) (\%) }\end{array}$} & $45-58$ & \multicolumn{2}{|c|}{$81 \cdot 2$} & \multicolumn{2}{|c|}{100} \\
\hline & $65-85$ & \multicolumn{2}{|c|}{$35 \cdot 7^{\star * *}$} & \multicolumn{2}{|c|}{$18 \cdot 2^{\star \star \star}$} \\
\hline \multirow[t]{2}{*}{ Chronic disease (\%) } & $45-58$ & \multicolumn{2}{|c|}{$56 \cdot 3$} & \multicolumn{2}{|c|}{$64 \cdot 3$} \\
\hline & $65-85$ & \multicolumn{2}{|c|}{$85 \cdot 7^{*}$} & \multicolumn{2}{|c|}{$93 \cdot 8$} \\
\hline \multirow[t]{2}{*}{ Smokers (\%) } & $45-58$ & \multicolumn{2}{|c|}{$18 \cdot 8$} & \multicolumn{2}{|c|}{$0 \dagger \dagger$} \\
\hline & $65-85$ & \multicolumn{2}{|c|}{21.4} & \multicolumn{2}{|c|}{$0 \dagger \dagger$} \\
\hline \multirow{2}{*}{$\begin{array}{l}\text { Exercise (weekly } \\
\text { frequency) }\end{array}$} & $45-58$ & 0.25 & 0.09 & 0.07 & $0 \cdot 10$ \\
\hline & $65-85$ & $0 \cdot 21$ & 0.10 & 0.06 & 0.09 \\
\hline
\end{tabular}

Value was significantly different from that of the $45-58$ years age group: ${ }^{\star} P<0.05$; *** $P<0.001$.

Value was significantly different from that of the men: $\dagger P<0.05$; $\dagger \dagger P<0.01$; †† $P<0.001$. complete the dietary, seasoning and preference questionnaire. After finishing the taste tests, while still completing the questionnaire, the participants were invited to eat freely from the salty and sweet snacks provided ${ }^{(21,22)}$.

In the second session, a week later, the participants were asked to again complete only the dietary questionnaire, but to recall their diets followed 20 years ago.

The test session for a participant lasted 60-80 min and was carried out by K. H. with one of two trained assistants. Appointments for the test sessions were based on calls to prayer (morning, midday, afternoon and evening). Of the sixty participants, forty were evaluated at the same time of day for both sessions and the remainder at adjacent time periods.

\section{Behavioural tests}

A battery of behavioural tests was designed to model different forms of salt intake. Unweighted scores were also combined to provide an operational definition of salt appetite ${ }^{(12,21-23)}$.

Determination of preferred amounts of salt in soup and sugar in tea. For this analysis, tomato soup was prepared by diluting one part of pure, unsalted tomato paste concentrate (22BX) with nine parts of boiled water and tea was prepared with a $3 \mathrm{~g}$ tea bag in 1 litre of boiled water. The soup and tea were prepared freshly before each test session and kept in vacuum flasks at approximately $45^{\circ} \mathrm{C}$.

The participants were presented with two $200 \mathrm{ml}$ cups of tomato soup, one unsalted and the other with $3.3 \%(\mathrm{w} / \mathrm{w})$ $\mathrm{NaCl}$. They were asked to taste the soup in both cups using a $5 \mathrm{ml}$ teaspoon and were provided with a third cup into which the experimenter then poured one-half of the unsalted soup. Then, using the teaspoon, they were asked to add the salted soup to the third cup and taste it until they deemed the mixture most 'tasty'. The salt concentration of the mixture was determined by weighing the cups, a validated measure of concentration. Preference for sugar in tea was determined similarly, using tea with $20 \%(\mathrm{w} / \mathrm{w})$ sucrose $^{(22)}$.

Psychophysical ratings of taste solutions in oral sprays using visual analogue scales. A psychophysical rating test was employed to rate intensity and preference for taste solutions. Solutions were diluted to six concentrations with bottled water $(9 \mathrm{mg} / \mathrm{l} \mathrm{Na})$. $\mathrm{NaCl}$ was diluted from $2.56 \mathrm{~m}$ by $1 / 3$ steps down to a concentration of $2.5 \mathrm{~mm}$ and sucrose from $135 \mathrm{~g} / \mathrm{l}$ by $1 / 2$ steps down to a concentration of $0.55 \mathrm{~g} / 1$. The experimenter sprayed $0.29 \mathrm{ml}$ of each taste solution at specific concentrations in fixed and counterbalanced semi-randomised orders (excluding sequential concentrations) onto the participant's tongue. Using visual analogue scales, the participants rated each concentration for taste intensity ('how strong is the taste?' - in Arabic) anchored by 'don't feel anything' and 'very strong' and for hedonics ('how tasty is it?') anchored by 'bad taste' and 'very tasty'.

Quantification of sweet and salty snacks consumed. The participants were invited to eat freely from two familiar commercial salty (890 and $780 \mathrm{mg} / 100 \mathrm{~g} \mathrm{Na}^{+}$) and sweet (120.5 and $146 \mathrm{mg} / 100 \mathrm{~g} \mathrm{Na}^{+}$) snack items presented on separate 
saucers in unwrapped bite-sized morsels. The number of morsels eaten was recorded discreetly.

Questionnaire. The investigator interviewed each participant using a questionnaire covering sixty-one food items of the common Israeli diet and particular to this community ${ }^{(22)}$. The questionnaire provided scores on the following components:

Dietary intakes: The participants were asked about their weekly frequency of consumption of food items and the quantities consumed. These were used to calculate $\mathrm{Na}^{+}$, carbohydrate, sweet carbohydrate, fat and protein contents of their daily diet using nutritional values and portion size tables $^{(24)}$.

Seasoning: The participants were asked how much sugar, salt, pepper, and oil/butter they added to season relevant food items (scored on a three-level scale). They were also asked about liking, licking and patterns of ingesting sugar, salt, pepper, and oil/butter. Only seasoning with salt and sugar was analysed.

Salt appetite. 'Salt appetite' is operationally defined as the (unweighted) mean ranks of the above measures (preferred amount of salt in soup, 640-mm $\mathrm{Na}$ spray, number of salty snacks eaten, dietary $\mathrm{Na}$ intake and salting). Equivalent sweet preference measures were calculated (preferred amount of sugar in tea, 9\% sucrose spray, number of sweet snacks eaten and sweetening) ${ }^{(22)}$. In addition, to examine the relationship of dietary $\mathrm{Na}$ intake with the other measures of salt preference and their relationships with other variables without the confound of the largely 'involuntary' dietary $\mathrm{Na}$ intake, a 'non-dietary salt appetite' measure that excluded dietary Na intake was derived.

Positive and Negative Affect Schedule. The PANAS contains two subscales of ten items each, each scored on a fivelevel scale. Positive affect items reflect a person's enthusiasm, activity, alertness, energy, full concentration and pleasurable engagement. Negative affect (NA) is general subjective distress subsuming a variety of aversive mood states ${ }^{(20)}$. The PANAS was translated into Arabic and back-translated by different colleagues and corrected accordingly. Two grammatical versions were used, masculine and feminine ${ }^{(25)}$.

\section{Statistical analysis}

The measures of salt preference, individually scored and also combined into 'salt appetite' as described, were compared between the groups using $t$ tests, ANOVA, correlations and regression analysis as appropriate (IBM SPSS Statistics version 19) and are reported.

The $\alpha$-value was fixed at $0 \cdot 05$, and means with their standard errors are the measures of variability. Non-significant results are not reported unless of specific interest.

\section{Results}

\section{Demographics}

Middle-aged female participants were found to be more obese than their male counterparts, whereas elderly male and female participants were found to have a similarly increased BMI (Table 1). Despite their greater BMI, middle-aged female participants, as well as elderly male and female participants, reported reduced energy intake (Table 2). Many of the older women reported voluntary restriction of their $\mathrm{Na}$ intake. Women reported less exercising than men and did not smoke in this ethnic group.

\section{Salt appetite and sweet preference}

The 20-year recalled dietary $\mathrm{Na}$ intake was greater than the current intake $(F(1,56)=58 \cdot 6, P<0 \cdot 001$; Table 2$)$. An interaction of the recalled dietary $\mathrm{Na}$ intake with $\operatorname{sex}(F(1,56)=5.9$, $P<0.05)$ and with age $(F(1,56)=7.5, P<0.01)$ was observed, because it was greater $(P<0 \cdot 001)$, especially in women $(P<0 \cdot 01)$. Middle-aged participants reported ingesting more dietary $\mathrm{Na}(P<0 \cdot 001)$ and also greater 20 -year recalled dietary $\mathrm{Na}$ intake $(P<0 \cdot 05)$. However, it is worth noting that the 20 -year recalled dietary $\mathrm{Na}$ intake reported by elderly participants was similar to the current $\mathrm{Na}$ intake reported by the 20 years' younger group.

The current dietary $\mathrm{Na}$ intake adjusted for energy intake (as covariate or as $\mathrm{Na}$ density) did not differ significantly by age, sex or their interaction. It was derived from dietary calculations and was correlated with energy intake, both current $(r$ 0.64, $P<0.001)$ and 20-year recalled $(r$ 0.45, $P<0 \cdot 001)$.

Salting habits do not vary with age, sex or recall.

The recalled dietary energy intake was greater than the current intake $(F(1,56)=80 \cdot 9, P<0 \cdot 001)$. There was an interaction between dietary energy intake and age $(F(1,56)=12 \cdot 6$, $P<0.001)$, as a greater increase was observed in middle-aged participants, and there was an age effect $(F(1,56)=22 \cdot 8$, $P<0 \cdot 001$ ), as elderly participants reported reduced intake.

Elderly participants reported greater sweet preference $(F(1,56)=6.3, P<0.05)$ and also greater 20-year recalled sweet preference $(F(1,56)=13 \cdot 0, P<0 \cdot 001)$.

An interaction between taste and sex was observed when assessing the number of salty and sweet snacks consumed $(F(1,56)=9 \cdot 56, P<0 \cdot 005)$.

An interaction between taste and age was observed when analysing salt appetite and sweet preference $(F(1,55)=9 \cdot 1$, $P<0.005)$, with the middle-aged participants preferring salt and the elderly participants preferring sweet. Salt appetite was found to be influenced by age $(F(1,55)=4 \cdot 3, P<0 \cdot 05)$, and a trend for the interaction between age and sex was observed $(F(1,55)=4 \cdot 0, \quad P=0 \cdot 05)$. Sweet preference was found to not differ by age or sex.

An interaction between sweet preference and age was observed when analysing non-dietary salt appetite (excluding dietary $\mathrm{Na}$ intake $)(F(1,55)=4.5, P<0.05)$, with a greater sweet preference being observed in elderly participants and a greater non-dietary salt appetite in middle-aged participants. Nevertheless, the effect of age on non-dietary salt appetite was not significant (Table 2). Interestingly, regression analysis showed that non-dietary salt appetite was also correlated with dietary energy intake $(t(2,58)=2.58, P<0.05)$, but not with dietary $\mathrm{Na}$ intake. 
Table 2. Results†

(Mean values with their standard errors)

\begin{tabular}{|c|c|c|c|c|c|c|c|c|c|}
\hline \multirow[t]{3}{*}{ Age (years)... } & \multicolumn{4}{|c|}{$45-58$} & \multicolumn{4}{|c|}{$65-85$} & \multirow[b]{3}{*}{ Group effects } \\
\hline & \multicolumn{2}{|c|}{ Men } & \multicolumn{2}{|c|}{ Women } & \multicolumn{2}{|c|}{ Men } & \multicolumn{2}{|c|}{ Women } & \\
\hline & Mean & SEM & Mean & SEM & Mean & SEM & Mean & SEM & \\
\hline Thirst VAS scores before test (mm) & 4.3 & $1 \cdot 2$ & $5 \cdot 8$ & 1.3 & 1.3 & 1.3 & 4.8 & $1 \cdot 2$ & $\operatorname{Age}^{\star \star \star} \operatorname{Sex}^{\star}$ \\
\hline Thirst VAS scores after test (mm) & $6 \cdot 7$ & $1 \cdot 1$ & $8 \cdot 0$ & $1 \cdot 2$ & 1.6 & $1 \cdot 2$ & 3.4 & 1.1 & Age $\times \operatorname{sex}^{*}$ \\
\hline Current water intake (cups/d) & $7 \cdot 1$ & $1 \cdot 3$ & 7.4 & 1.4 & $6 \cdot 6$ & 1.4 & $5 \cdot 6$ & 1.3 & \\
\hline Water intake 20 years ago (cups/d) & $6 \cdot 2$ & 1.7 & $6 \cdot 9$ & 1.8 & $8 \cdot 9$ & 1.8 & $6 \cdot 6$ & 1.7 & \\
\hline Current dietary energy intake & & & & & & & & & $\mathrm{Age}^{\star \star \star}$ \\
\hline $\mathrm{kJ}$ & 17518 & 1188 & 13807 & 1276 & 11297 & 1276 & 10916 & 1192 & \\
\hline kcal & 4187 & 284 & 3300 & 305 & 2700 & 305 & 2609 & 285 & \\
\hline Dietary energy intake 20 years ago & & & & & & & & & Age $\times 20$ years $^{\star * *}$ \\
\hline $\mathrm{kJ}$ & 27313 & 2410 & 29050 & 2573 & 15673 & 2573 & 17401 & 2410 & \\
\hline kcal & 6528 & 576 & 6943 & 615 & 3746 & 615 & 4159 & 576 & \\
\hline Current dietary $\mathrm{Na}^{+}$intake $\ddagger(\mathrm{mg} / \mathrm{d})$ & 8258 & 600 & 5923 & 642 & 4772 & 642 & 5200 & 600 & $\mathrm{Sex}^{\star} \mathrm{Age}^{\star \star}$ \\
\hline Dietary $\mathrm{Na}^{+}$intake 20 years ago $(\mathrm{mg} / \mathrm{d})$ & 11784 & 1198 & 13781 & 1280 & 6976 & 1280 & 8394 & 1198 & \\
\hline Current salting & 0.57 & 0.11 & 0.39 & 0.09 & $0 \cdot 18$ & 0.09 & 0.37 & 0.10 & \\
\hline Salting 20 years ago & 0.52 & 0.11 & 0.34 & 0.08 & 0.31 & 0.10 & 0.40 & 0.11 & \\
\hline Current sweetening & 0.38 & 0.06 & 0.65 & 0.15 & 0.66 & 0.14 & 0.84 & 0.15 & Age $^{*}$ \\
\hline Sweetening 20 years ago & 0.58 & 0.14 & 0.72 & 0.13 & 1.00 & 0.20 & 1.25 & 0.23 & Age $\times 20$ years $^{\star \star \star}$ \\
\hline Percentage of salt in soup & 1.40 & 0.12 & $1 \cdot 30$ & 0.13 & $1 \cdot 16$ & $1 \cdot 13$ & $1 \cdot 17$ & $1 \cdot 12$ & \\
\hline Percentage of sugar in tea & $9 \cdot 60$ & 0.70 & 9.73 & 0.85 & $9 \cdot 11$ & 0.64 & $9 \cdot 76$ & 0.83 & \\
\hline Salty snacks consumed & 1.7 & 0.9 & 4.4 & $1 \cdot 8$ & 1.7 & 0.7 & $3 \cdot 1$ & $1 \cdot 0$ & Taste $\times \operatorname{sex}^{\star \star}$ \\
\hline Sweet snacks consumed & $2 \cdot 5$ & $1 \cdot 1$ & 0.64 & $0 \cdot 2$ & $2 \cdot 4$ & 1.0 & $1 \cdot 3$ & 0.4 & \\
\hline Salt appetite & $36 \cdot 1$ & $2 \cdot 2$ & 29.6 & $2 \cdot 4$ & $26 \cdot 8$ & $2 \cdot 4$ & $29 \cdot 4$ & $2 \cdot 3$ & Age $^{*}$ (salt) \\
\hline Sweet preference & 28.9 & $2 \cdot 4$ & $27 \cdot 8$ & $2 \cdot 6$ & $31 \cdot 3$ & $2 \cdot 6$ & 33.7 & 2.5 & Taste $\times$ age ${ }^{\star \star}$ \\
\hline Non-dietary salt appetite & $32 \cdot 5$ & $2 \cdot 4$ & $32 \cdot 1$ & $2 \cdot 6$ & $25 \cdot 8$ & $2 \cdot 6$ & $31 \cdot 2$ & 2.5 & \\
\hline
\end{tabular}

VAS, visual analogue scale.

${ }^{\star} P<0.05,{ }^{\star \star} P<0.01,{ }^{\star \star \star} P<0.001$.

†For compactness only significant interactions are reported (see text for lower-order comparisons).

$\ddagger$ Differences in dietary $\mathrm{Na}$ intake are explained by differences in dietary energy intake.

\section{Psychophysical evaluations}

In Fig. 1, sensory evaluations of concentration and hedonics for salt and sweet oral sprays are shown. Other than the expected effects of concentration and taste, there were no significant group effects, although women tended to find sucrose more hedonic (men 4.4 (SE 0.5); women 5.9 (SE 0.5); $P<0.05$ ).

\section{Thirst}

The means of the appetite measures, including thirst, are given in Table 2 . While evaluating the changes in thirst visual analogue scale scores over the duration of the test, an effect of age $(F(1,56)=11.7, P<0.001)$ and of sex $(F(1,56)=4 \cdot 1, P<0.05)$ and an interaction between sex and age $(F(1,56)=4.9, P<0.05)$ were observed, because elderly participants did not report an increase in thirst, unlike middle-aged participants, and female participants reported being thirstier, particularly elderly women.

Water intake (cups/d) was found to not vary with age, sex or 20-year recall.

\section{Positive and Negative Affect Schedule}

Positive affect was lower in elderly participants (27.7 (SE 1.4) $v$. $31 \cdot 4$ (SE 0.9), $F(1,56)=5 \cdot 1, P<0 \cdot 05)$, and NA was significantly higher in women $(21 \cdot 8(\operatorname{se~} 1 \cdot 4) v .14 \cdot 2(\operatorname{se~} 1 \cdot 4), F(1,56)=15 \cdot 1$, (a)

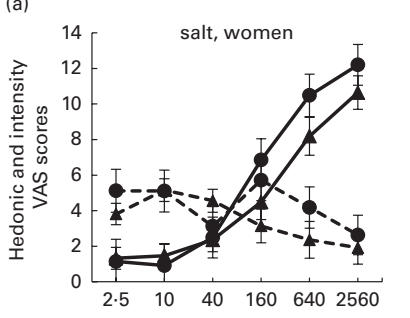

Sodium chloride concentration (mM)

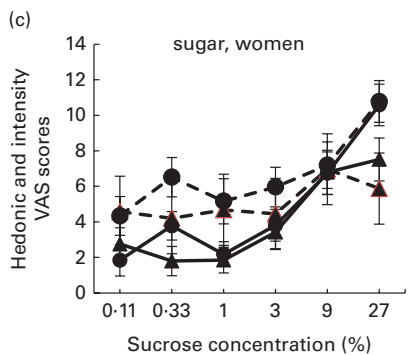

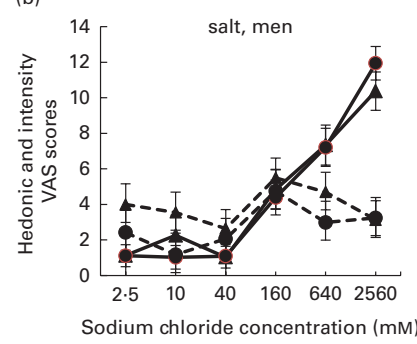

(d)

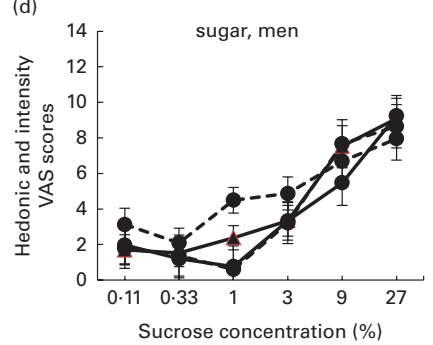

Fig. 1. Taste intensity and hedonics for salt ((a) women and (b) men) and sucrose ((c) women and (d) men) solutions delivered by oral spray. There was no difference in taste hedonics or taste intensity by age or sex. VAS,

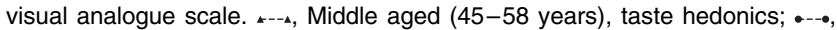
aged (65-85 years), taste hedonics; $\longleftrightarrow$, middle aged (45-58 years), taste intensity; $\bullet$. aged (65-85 years), taste intensity. (A colour version of this figure can be found online at http://www.journals.cambridge.org/bjn). 
$P<0 \cdot 001$ ), suggesting much higher levels of depression and anxiety than among men.

\section{Hypothesised correlations}

Mood. There was no significant relationship between $\mathrm{Na}$ and mood (PANAS). However, sweet preference was found to be related to NA in middle-aged female participants ( $r 0.55, P<0.05$ ) and to positive affect in the middle-aged male participants $(r 0.54, P<0.05)$.

NA was found to be correlated with the use of medication in middle-aged participants $(r 0.35, P<0.05)$.

Nocturia. The night frequency of nocturia was found to be not significantly related to any measure of salt appetite or fluid intake.

Nocturia was found to be correlated with NA (0.29, $P<0.05)$, and women reported having more frequent nocturia than men $(F(1,56)=12 \cdot 1, P<0.001,2.33($ SE 0.23) $v .1 .21$ (SE $0 \cdot 23)$ ), consistent with their greater NA.

Sleep. Dietary Na intake was found to be related to sleep duration in middle-aged participants $(0.40, P<0.05)$, but the effect was equally correlated with dietary energy intake (0.41, $P<0 \cdot 05)$. Sleep duration was found to be inversely related to sweet preference among women $(-0 \cdot 48, P<0 \cdot 01)$.

Elderly participants reported sleeping less at night (4.3 (SE 0.3) v. $5 \cdot 5($ SE 0.3$) \mathrm{h}, P<0.01)$.

\section{Discussion}

We found no clear impairment of salt appetite in elderly participants when compared with middle-aged participants. Although elderly men (but not women) have a lesser salt appetite (as defined above) than their middle-aged counterparts, this is best understood as an artifact due to reduced energy intake in the elderly, in turn reducing dietary $\mathrm{Na}$ intake, and therefore it is not a specific reduction in salt avidity. There were no age-related differences in the intensity of taste or hedonic profile of $\mathrm{Na}$ or changes in the reported amount of salting over the years as well as no age-related differences in salting soup or number of salty snacks consumed. No age-related sex differences were observed, although men tended to prefer salt more and women sweet ${ }^{(12)}$.

Because salt appetite excluding dietary $\mathrm{Na}$ intake does not differ with age, it would seem equally unlikely that the reduction in total dietary intake is due to reduced salt appetite in the elderly, despite the close correlation of dietary energy and $\mathrm{Na}$ intakes.

In the absence of documentation in this community, we asked the study participants to recall their dietary intake 20 years ago to assess whether diet composition and $\mathrm{Na}$ intake differed by generation or had changed during the past 20 years. We found that the recalled dietary $\mathrm{Na}$ intake was greater than the current intake, especially in women. However, while elderly participants reported ingesting less dietary $\mathrm{Na}$, their 20-year recalled $\mathrm{Na}$ intake was found to match the current intake of the 20 years' younger group. Moreover, analysis (data not shown) revealed that only two to three dietary items of the sixty-one items differed in the current and recalled diets, although most were present at greater amounts in the recalled diet.

The diet was mostly home prepared. Items eaten most (by energy) were pita and chocolate, followed by cookies, chicken schnitzel and red meat, and then fresh fruit and sweet beverages.

Together, these suggest that the reduced intake in the elderly is indeed due to ageing rather than due to dietary changes over time.

Clearly, diets recalled from 20 years ago are not validated, and a correlation with the current dietary intake may be imposed by the questionnaire and context despite separating the questionnaire administration by days. On the other hand, the interesting correlation with BMI (below) lends some validity to the measure.

In contrast to the intact salt appetite in the elderly, we found that elderly participants were less thirsty at the beginning of the test session and that during the test session they did not report an increase in thirst, whereas middle-aged participants did so by almost $50 \%$. Elderly participants did not recall greater drinking or liking for water 20 years ago, possibly because impaired thirst may also limit retroactive awareness of thirst.

We found that women were thirstier than men. This confirms an earlier hypothesis that because men concentrate urine more and their thirst/vasopressin system has higher thresholds, they might drink less than women, and this is consistent with findings in older women who drink more than men after exercise ${ }^{(26,27)}$.

Contrary to our hypothesis, we found no relationship between $\mathrm{Na}$ intake and mood measured by the PANAS. Confirming the validity of our measurements, positive affect was lower and NA higher in women in accordance with their known higher levels of depression ${ }^{(15)}$. In a sample of some 10000 people (US National Health and Nutrition Survey, 2007-2008), dietary $\mathrm{Na}$ intake was found to be related to depression, while amount of salt preferred was found to be inversely related to depression, suggesting self-medication ${ }^{(15)}$ However, the effects are small and may not emerge in a smaller sample, with a different measuring instrument, and ethnically homogeneous. Moreover, none of the present study participants met the criteria for severe depression, so that restricted variability in the PANAS scores may limit the scope for demonstrating any relationship with salt appetite $(15,28)$

Among the middle-aged participants, sweet preference was found to be related to positive mood in men and negative mood in women. Anhedonia to sweet taste is a well-validated model of depression in animal research, but in human research increased intake of sweets is more often associated with depression $^{(29,30,31)}$. NA was much higher in women in the present study and may be related to their sweet preference - remarkably similar findings have been reported recently in French women ${ }^{(31)}$

In men, the greater intake of salt, even when adjusted for body weight, and the greater preference for salt might be related to their greater lean body mass and greater sweat rates, possibilities remaining to be investigated ${ }^{(12,15,19)}$.

Also, in contradiction to our hypotheses, the frequency of nocturia was found to be not significantly related to any measure of salt appetite. Nor was it related to fluid, water, 
beverage or soft-drink intake (data not shown), did not vary with age, and was not related to sleep duration.

Female participants reported more frequent nocturia when compared with male participants. This has been reported in younger women, but the present study sample differs from that of other studies in which frequency and incidence were found to be higher in men, although, similar to us, they reported similar rates for the elderly ${ }^{(32)}$. It is possible that volume and concentration of night urine are influenced by $\mathrm{Na}$ and fluid intakes, which may not influence the frequency of nocturia ${ }^{(32)}$.

The frequency of nocturia is related to NA, possibly reflecting the known relationship of depression and troubled sleep, although we did not find an association of sleep duration with PANAS scores. Sleep duration in this population may be assessed and reported differently - the day is partitioned by calls to prayer (5-6 a day, commencing at approximately 04.00 hours) rather than clock time. In addition, afternoon sleep is customary, especially among elderly women, and may have contributed to the short night-sleep duration reported. Despite this, the known briefer sleep duration in the elderly was clearly evident, suggesting that any robust influence of $\mathrm{Na}$ intake or appetite could have emerged. The absence of an association between $\mathrm{Na}$ and sleep is in line with an analysis of National Health and Nutrition Survey (USA) data ${ }^{(15)}$

The participants of the present study reported high $\mathrm{Na}$ and energy intakes, which were confirmed in a retest of the participants with more extreme values. Both intakes were substantially higher than those from another report from Israel ${ }^{(33)}$. However, the high BMI that we found is generally consistent with that report and more compatible with the high energy intake that we found.

Despite their greater BMI, middle-aged female and elderly male and female participants reported reduced energy intake. Although the under-reporting of dietary intake is known, particularly in obese (e.g. Archer et al. ${ }^{(34)}$ ), the discrepancy observed in the present study may be explained by prior energy intake, thus the correlation of BMI with the 20-year recalled dietary energy intake among men $(r 0.46, P<0.05)$, but not with the current energy intake. In addition, we found that more elderly participants reported dieting (data not shown), again suggesting that BMI may have increased earlier in life and is less related to the current energy intake.

It is not clear why salt appetite is not impaired in the elderly, but thirst is. Thirst is aroused by dehydration and depends on physiological substrates that function less well in the elderly possibly related to changes in volumetric, rather than osmotic, thirst mechanisms ${ }^{(4-9,35)}$, although changes in higher cortical functioning might also contribute $^{(36)}$. Although old rats drink lesser amounts of saline solution than middle-aged rats, the amounts of saline ingested are 'still copious and comprise an unambiguous demonstration of salt appetite in old rats ${ }^{,(37)}$. Moreover, recent findings in the Fischer $344 \times$ Brown Norway rat suggest that it might be a useful model for mineralofluid regulation in elderly humans because it 'support(s) the idea that impairments in behaviour contribute more to the waning ability of ageing animals to respond to body fluid challenges than do declines in kidney function. In addition, the results suggest that the behavioural defence of Na homeostasis is less diminished with age compared with other strains so far studied ${ }^{\text {,(38). }}$.

In humans, salt appetite may be a conditioned preference, as we have shown in exercisers losing $\mathrm{Na}$ in sweat and in the robust salt appetite persisting over decades among urbanised Bedouin, equalling that of their desert-dwelling encampment contemporaries ${ }^{(36,39,40)}$. Moreover, early Na loss engenders an enduring enhanced salt appetite in humans and rats $^{(12,21,41-43)}$. For these reasons, salt appetite in the elderly may be maintained despite physiological changes with age.

\section{Conclusions}

We found that salt appetite in the elderly is intact. Salt appetite as operationally defined to represent various forms of salt intake includes questionnaire-derived dietary $\mathrm{Na}$ intake, salting, liking for salt, laboratory tests of hedonics of saline solutions, preferred amounts of salt in soup, and number of salty snacks consumed ${ }^{(12)}$.

Reduced dietary $\mathrm{Na}$ intake in elderly men, and the recent nuanced understanding of the lower hypertension risk, cardiovascular health, and increased longevity with $\mathrm{Na}$ intake within $2 \cdot 5-6.0 \mathrm{~g} / \mathrm{d}^{(44,45)}$, might suggest that $\mathrm{Na}$ supplementation in the elderly could be judiciously considered $^{(5)}$. Where salt sensitivity is not suspected, salt appetite might be utilised to improve the well-being of the elderly and $\mathrm{Na}$ supplementation where hyponatraemia is suspected, and isotonic drinks might be beneficial to counter age-related loss of appetite and to stimulate thirst ${ }^{(5,46)}$.

Finally, the findings reinforce the view that $\mathrm{Na}$ intake in humans is not physiologically driven ${ }^{(12,19)}$, unlike in animals, in which it is exquisitely physiologically regulated, and partially impaired in aged rats ${ }^{(13,15,37)}$.

\section{Acknowledgements}

The present study received financial support from the Salt Institute and the University of Haifa. The funders had no role in the design and analysis of the study or in the writing of this article.

The authors' contributions are as follows: M. L. formulated the research questions, M. L. and K. H. designed the study, analysed the data and wrote the article; K. H. carried out the experiments.

The authors have no conflicts of interest to declare.

\section{References}

1. De Luca LA Jr, Vendramini RC, Pereira DT, et al. (2007) Water deprivation and the double-depletion hypothesis common neural mechanisms underlie thirst and salt appetite. Braz J Med Biol Res 40, 707-712.

2. Fitzsimons JT (1998) Angiotensin, thirst, and sodium appetite. Physiol Rev 78, 583-640.

3. Denton D, Shade R, Zamarippa F, et al. (1999) Neuroimaging of genesis and satiation of thirst and an interoceptor-driven theory of origins of primary consciousness. Proc Natl Acad Sci U S A 96, 5304-5309. 
4. Cowen LE, Hodak SP \& Verbalis JG (2013) Age-associated abnormalities of water homeostasis. Endocrinol Metab Clin North Am 42, 349-370.

5. Fusgen I (2003) Disorders of water and sodium metabolism in older patients. Eur J Geriatr 03/04, 1-4.

6. Kenney W \& Chiu P (2000) Influence of age on thirst and fluid intake. Med Sci Sports Exerc 33, 1524-1532.

7. Liamis G, Rodenburg EM, Hofman A, et al. (2013) Electrolyte disorders in community subjects: prevalence and risk factors. Am J Med 126, 256-263.

8. McKinley MJ, Cairns MJ, Denton DA, et al. (2004) Physiological and path physiological influences on thirst. Physiol Behav 81, 795-803

9. Zizza CA, Kathy JE, Catherine M, et al. (2009) Total water intakes of community-living middle-old and oldest-old adults. J Gerontol A Biol Sci Med Sci 64A, 481-486.

10. Hoorn EJ \& Zietse R (2012) Hyponatremia and mortality: moving beyond associations. Am J Kidney Dis 362, 139-149.

11. Verbalis JG, Barsony J, Sugimura Y, et al. (2010) Hyponatremia-induced osteoporosis. J Bone Miner Res 25, 554-563.

12. Leshem M (2009) Biobehavior of the human love of salt. Neurosci Biobehav Rev 3, 1-17.

13. Begg DP, Sinclair AJ \& Weisinger RS (2012) Reductions in water and sodium intake by aged male and female rats. Nutr Res 32, 865-872.

14. McKinley MJ, Denton DA, Thomas CJ, et al. (2006) Differential effects of aging on fluid intake in response to hypovolemia, hypertonicity, and hormonal stimuli in Munich Wistar rats. Proc Natl Acad Sci US A 103, 3450-3455.

15. Thunhorst RL \& Johnson AK (2003) Thirst and salt appetite responses in young and old Brown Norway rats. Am J Physiol Regul Integr Comp Physiol 284, R317-R327.

16. Goldstein P \& Leshem M (2014) Dietary sodium, added salt, and serum sodium associations with growth and depression in the U.S. general population. Appetite 79, 83-90.

17. Morris MJ, Na ES \& Johnson AK (2008) Salt craving: the psychobiology of pathogenic sodium intake. Physiol Behav $\mathbf{9 4}$, 709-721.

18. Vitiello M, Prinz P \& Halter J (1983) Sodium-restricted diet increases nighttime plasma norepinephrine and impairs sleep patterns in man. J Clin Endocrinol Metab 56, 553-556.

19. Leshem M (2013) The human penchant for deranged salt balance. In Neurobiology of Body Fluid Homeostasis (Transduction and Integration), 1st ed., pp. 1-22 [L De Luca, JV Menani and AK Johnson, editors]. Boca Raton, FL: Taylor \& Francis Group.

20. Watson D, Clark LA \& Tellegen A (1988) Development and validation of brief measures of positive and negative affect: the PANAS scales. J Pers Soc Psychol 54, 1063-1070.

21. Crystal SR \& Bernstein IL (1995) Morning sickness: impact on offspring salt preference. Appetite 25, 231-240.

22. Kochli A, Rakover Y \& Leshem M (2005) Increased salt appetite in patients with congenital adrenal hyperplasia 21-hydroxylase deficiency. Am J Physiol 288, R1673-R1681.

23. Stone LJ \& Pangborn RM (1990) Preferences and intake measures of salt and sugar, and their relation to personality traits. Appetite 15, 63-79.

24. Meir C \& Reshef A (1997) Tables of Food Constituents. Jerusalem: Ministry of Health, Department of Nutrition (Hebrew).

25. Leshem M, Sliman W \& Taweel S (2014) Patient mood flux on- and off-hemodialysis. Hemodial Int 18, 488-494.

26. Baker LB, Munce TA \& Kenney WL (2005) Sex differences in voluntary fluid intake by older adults during exercise. Med Sci Sports Exerc 37, 789-796.
27. Perucca J, Bouby N, Valeix P, et al. (2006) Sex difference in urine concentration across differing ages, sodium intake, and level of kidney disease. Am J Physiol Regul Integr Comp Physiol 292, 700-705.

28. Aldinger M, Stopsack M, Barnow S, et al. (2013) The association between depressive symptoms and emotion recognition is moderated by emotion regulation. Psychiatry Res 205, 59-66.

29. Leshem M (2011) Low dietary sodium is anxiogenic in rats. Physiol Behav 103, 453-458.

30. Jeffery RW, Linde JA, Simon GE, et al. (2009) Reported food choices in older women in relation to body mass index and depressive symptoms. Appetite 52, 238-240.

31. Camilleri GM, Méjean C, Kesse-Guyot E, et al. (2014) The associations between emotional eating and consumption of energy-dense snack foods are modified by sex and depressive symptomatology. J Nutr 144, 1264-1273.

32. Bosch JL \& Weiss JP (2013) The prevalence and causes of nocturia. J Urol 89, Suppl. 1, S86-S92.

33. MABAT - First Israeli National Health and Nutrition Survey 1999-2001 (2004) Food and Nutrition Services, Israel Ministry of Health. Publication 228, Israel.

34. Archer E, Hand GA \& Blair SN (2013) Validity of U.S. nutritional surveillance: National Health and Nutrition Examination Survey caloric energy intake data, 1971-2010. PLOS ONE 98, e76632.

35. Stachenfeld NS, DiPietro L, Nadel ER, et al. (1997) Mechanism of attenuated thirst in aging: role of central volume receptors. Am J Physiol 272, R148-R157.

36. Farrell MJ, Zamarripa F, Shade R, et al. (2008) Effect of aging on regional cerebral blood flow responses associated with osmotic thirst and its satiation by water drinking: a PET study. Proc Natl Acad Sci US A 105, 382-387.

37. Thunhorst RL, Beltz TG \& Johnson AK (2013) Effects of aging on mineralocorticoid-induced salt appetite in rats. Am J Physiol Regul Integr Comp Physiol 305, R1498-R1505.

38. Thunhorst RL, Beltz T \& Johnson AK (2014) Age-related declines in thirst and salt appetite responses in male Fischer $344 \times$ Brown Norway rats. Physiol Behav 135, 180-188.

39. Leshem M, Saadi A, Alem N, et al. (2007) Enhanced salt appetite, diet and drinking in traditional Bedouin women in the Negev. Appetite 50, 71-82.

40. Wald N \& Leshem M (2003) Salt conditions a flavor preference or aversion after exercise depending on $\mathrm{NaCl}$ dose and sweat loss. Appetite 40, 277-284.

41. Leshem M (1998) Salt preference in adolescence is predicted by common prenatal and childhood mineralofluid loss. Physiol Behav 63, 699-704.

42. Leshem M (2009) The excess salt appetite of humans is not due to sodium loss in adulthood. Physiol Behav $\mathbf{9 8}$ $331-337$.

43. Stein LJ, Cowart BJ, Epstein AN, et al. (1996) Increased liking for salty foods in adolescents exposed during infancy to a chloride-deficient feeding formula. Appetite 27, 65-77.

44. Alderman MH (2010) Reducing dietary sodium. JAMA 303, 448-494

45. Strom BL, Anderson CA \& Ix JH (2013) Sodium reduction in populations: insights from the Institute of Medicine committee. JAMA 310, 31-32.

46. Schiffman S \& Graham BG (2000) Taste and smell perception affect appetite and immunity in the elderly. Eur J Clin Nutr 54, 54-63. 